\title{
Persistent Left Ventrienlar Dysfunction in a Teenager with Yellow Phosphorous Poisoning
}

Pooja PS, Padmakumar AV, Chandan Garud Suresh

Department of Medical Intensive Care Unit, Fortis Healthcare Limited, Bannerghatta Road, Bengaluru-560076, Karnataka, India.

\section{Abstract:}

Yellow phosphorous is a chemical compound used widely as a rodenticide and in fireworks. Due to its easy availability in India, consumption with suicidal intention is common. Liver is the organ most commonly involved. Though cardio-toxicity manifesting as hypotension, tachycardia, arrhythmias and transient electrocardiogram changes is well known, a persistent left ventricular dysfunction is yet to be reported. We report a case of persistent left ventricular dysfunction as a long term sequelae in a teenager with intentional consumption of this compound.

Key words: Arrhythmias, Rodenticides, Ventricular Dysfunction, Hypotension, Electrocardiography.

\section{Introduction}

Yellow phosphorous is a substance used widely in rodenticide and in fireworks. With exposure it is known to target liver, kidney, brain and heart. The mortality with ingestion of this agent has been reported previously to be between 10 $50 \%$ [1]. It primarily affects the liver causing acute hepatic failure, coagulopathy and hepatic encephalopathy in a spectrum of multiorgan failure. Hypotension, tachycardia, arrhythmias and transient ECG changes have been reported as early cardiac manifestations. However, no long term cardiac sequelae have been found in human studies [2]. We report the possibility of persistent left ventricular dysfunction following ingestion of yellow phosphorous in this case report.

\section{Case Report}

A 14 year old boy presented with alleged suicidal ingestion of an unknown quantity of rodenticide commonly known as RATOL 3\% (containing 3\% phosphorous). At a local hospital he was initially treated with gastric lavage and was monitored in the intensive care unit (ICU). He was referred to our tertiary center on day 5 for possible liver transplantation in view of worsening liver function and hepatic encephalopathy.

On admission to our unit, he had fulminant hepatic failure with acute kidney injury. He was intubated and mechanically ventilated in view of his worsening hepatic encephalopathy. His laboratory investigations on admissions were as

Corresponding Author: Dr. Pooja PS

Email: pooja_ps@yahoo.com

Received: November 24, 2014 | Accepted: March 11, 2015 | Published Online: March 30, 2015

This is an Open Access article distributed under the terms of the Creative Commons Attribution License (creativecommons.org/licenses/by/3.0)

Conflict of interest: None declared | Source of funding: Nil | DOl: http://dx.doi.org/10.17659/01.2015.0034 
per table 1. His initial electrocardiogram (ECG), echocardiogram and ultrasound abdomen were normal. Computed tomography of brain showed mild cerebral edema. He was managed with vitamin $\mathrm{K}$, anti-encephalopathy measures and fresh frozen plasma in view of mucosal bleeding. On day 8 , his liver function tests, coagulation and renal function started improving. However, on day 10 , his ventilatory requirements increased and he became progressively hypotensive with chest $\mathrm{x}$-ray showing bilateral new infiltrates [Fig.1]. His ECG showed new onset ST changes and deep inverted T waves. Cardiology opinion was taken and repeat echocardiogram showed global left ventricle (LV) dysfunction with dilated cardiac chambers and ejection fraction of $44 \%$ [Fig.2]. His white cell counts were within normal range and repeated cultures failed to reveal any specific organism or septic foci. He was managed with dobutamine and diuretics for the next few days. In view of persistent LV dysfunction he was started on digoxin. Tracheostomy was done on day 13 and he was gradually weaned off from the ventilator over the next few days. At discharge from ICU on day 27, repeat echocardiogram showed persistent global LV dysfunction. On further follow up, he continued to have LV dysfunction even at 6 months after discharge from the hospital.

\section{Discussion}

Yellow phosphorous is an inorganic substance also known as white phosphorous, used primarily in military ammunition, fire crackers, fertilizers and rodenticides. In India it is readily available and commonly used as a rodenticide paste or powder containing $2-5 \%$ of yellow phosphorous. The toxic dose ranges from $15-100 \mathrm{mg}$. Therefore, in a 70 $\mathrm{kg}$ adult the dose would be approximately 0.2-1.4 $\mathrm{mg} / \mathrm{kg}$ [3]. The fatality rate has previously been reported to be between 10-50\% [1]. Fernandez and Cannarez, in their series of 15 patients have reported a mortality of $27 \%$ which confirms that yellow phosphorous is extremely lethal when ingested
Table 1: Laboratory investigations on admission

\begin{tabular}{|l|l|l|l|}
\hline SGOT & $1644 \mathrm{U} / \mathrm{L}$ & Platelet Count & $81000 / \mu \mathrm{L}$ \\
\hline SGPT & $943 \mathrm{U} / \mathrm{L}$ & Creatinine & $1.7 \mathrm{mg} / \mathrm{dL}$ \\
\hline INR & 6.08 & Ammonia & $109 \mu \mathrm{mol} / \mathrm{L}$ \\
\hline aPTT & $>100 \mathrm{sec}$ & Total Bilirubin & $4.21 \mathrm{mg} / \mathrm{dL}$ \\
\hline GGT & $198 \mathrm{U} / \mathrm{L}$ & Direct Bilirubin & $3.70 \mathrm{mg} / \mathrm{dL}$ \\
\hline LDH & $2540 \mathrm{U} / \mathrm{L}$ & Alkaline phosphatase & $658 \mathrm{U} / \mathrm{L}$ \\
\hline
\end{tabular}

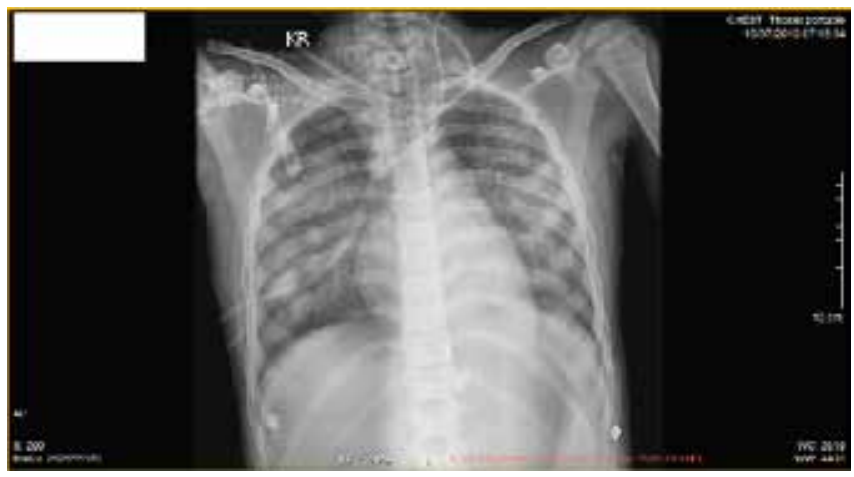

Fig.1: Chest X-ray showing bilateral lung parenchymal involvement.

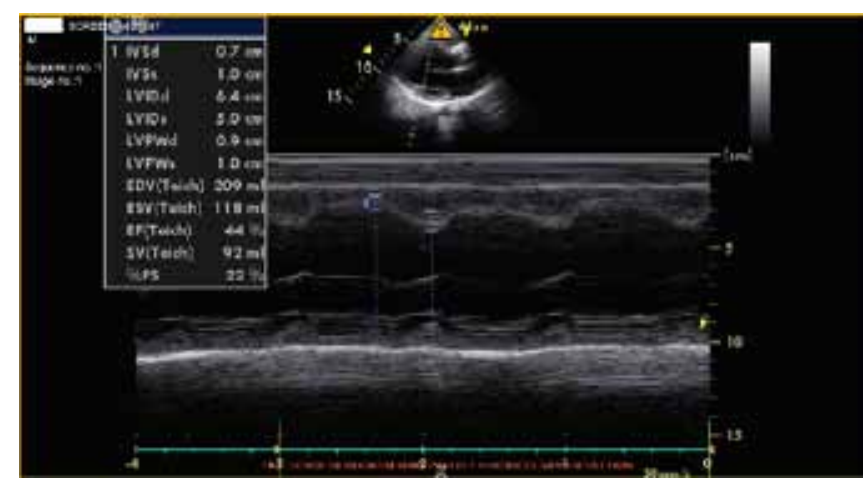

Fig.2: Echocardiogram suggestive of left ventricular dysfunction and dilatation of cardiac chambers.

[4]. After absorption from the gastrointestinal (GI) tract it is distributed to all tissues, particularly the liver with peak levels after 2-4 hours of ingestion. Phosphorous remains stable in the gut for long periods due to low oxygen tension [5]. It is a protoplasmic poison causing cardiac, hepatic and 
renal failure. 3 stages have been described after its ingestion. The $1^{\text {st }}$ stage occurs during the $1^{\text {st }} 24$ hours in which patient is either asymptomatic or has some sign and symptoms of $\mathrm{Gl}$ irritation. The $2^{\text {nd }}$ stage occurs between 24-72 hours after ingestion where he is asymptomatic and may be discharged prematurely. There may be mild elevation of liver enzymes and bilirubin in this stage. The $3^{\text {rd }}$ stage occurs after 72 hours until the resolution of symptoms or death. This stage is characterized by multiorgan failure $[5,6]$. Our patient presented to us in stage 3 with encephalopathy, acute liver failure, acute kidney injury and coagulopathy.

Acute hepatic failure, coagulopathy, deranged liver functions are the most common presentation. Central nervous system effects reported are altered mental status, psychosis, hallucinations and coma. Some patients also develop acute tubular necrosis (ATN) and present with acute kidney injury. In our case, the hepatic and renal dysfunction was self-limiting and recovered with supportive therapy.

Cardiac toxicity includes hypotension, tachycardia and arrhythmia [7]. Alteration in ECG such as inverted T waves, changes in QRS complex, tachycardia, arrhythmias may be seen. Also, decreased ventricular contractility has been reported [2]. In a cross sectional study where 85 patients were studied, dysrhythmias were noted in only two patients, another four showed tachybradycardia [8]. Damage to myocardium on post mortem histological examination was seen in a number of cases. This included fatty infiltration of the muscle, necrosis of myocardium, markedly dilated heart chambers, interstitial edema of myocardium, vacuolation of cells, and prominent cross striations. However no long-term cardiac effects have been reported in human studies [2]. Pathological changes in heart were also reported by Tally et al. [7].
Early cardiovascular collapse has been attributed to fluid and electrolyte loss due to persistent vomiting in addition to cardio toxicity [9-11]. Our patient manifested with hypotension, tachycardia and acute pulmonary edema as a consequence of LV failure. His cardiac involvement started after 72 hours of consumption, thus emphasizing the importance of anticipating this complication as a delayed manifestation. This presentation can complicate the preexistent multiorgan failure. Digoxin was well tolerated as renal and hepatic function had improved. No measures have been described to limit cardiac toxicity. The persistence of left ventricular dysfunction after the resolution of multiorgan involvement even beyond 6 months is rare and not documented in literature.

There is no specific antidote for yellow phosphorous. Treatments include removal of poison and prevent further exposure with gastric lavage using saline and potassium permagnate (which can oxidise phosphorous) [5]. Liver transplantation should be performed in suitable candidates $[12,13]$.

\section{Conclusion}

Our case report highlights the possibility of late onset persistent left ventricular dysfunction as a long term sequelae with yellow phosphorous poisoning necessitating a high index of suspicion for the same.

\section{References}

1. Pande TK, Pandey S. White phosphorous poisoning -explosive encounter. J Assoc Physicians India. 2004;52:249-250.

2. Health effects. Toxicology profile for white phosphorous, Agency for Toxic substance and Disease registry: Sep 1997, pp. 51. Available from: http://www.atsdr.cdc.gov/toxprofiles/ tp 103.pdf. Accessed November 24,2014.

3. Loai Nabil Al Barqouni, Sobhi L Skaik, Nafiz R 
Abu Shaban, Nabil Barqouni. White phosphorus burn. The Lancet. 2010;376-368.

4. Fernandez OU, Canizares LL. Acute hepatotoxicity from ingestion of Yellow Phosphorous containing fireworks. J Clin Gastroenterol. 1995;21:139-142.

5. Brent J, Wallace K, Burkhart K. Critical Care Toxicology: Diagnosis and Management of the Critically Poisoned Patient. Philadelphia, PA: Elsievers Saunders;2005:851-861.

6. Mccarron MM, Gaddis GP, Trotter AT. Acute yellow phosphorous poisoning from pesticide pastes. Clin Toxicol. 1981;18:693-712.

7. Talley RC, Linhart JW, Trevino AJ, Moore L. Acute elemental phosphorus poisoning in man: Cardiovascular toxicity. Am Heart J. 1972;84:139-140.

8. Fabrico Gonzalez-Andrade, Ramiro LopezPulles. White phosphorous poisoning by oral ingestion of fire crackers or little devils: Current experience in Ecuador. Clinical Toxicology. $2011 ; 49: 29-33$.
9. Ramirez MS, Pacheco J, Gomez N, Fuentes S. Pediatric poisoning by white phosphorous. Survival of potentially lethal dose intake. Arch Venez Pueri Pediat. 2008;71:140-144.

10. Gonzalez -Andrade F, Lopez -Pulles R, Estevez E. Acute pesticide poisoning in Ecuador: a short epidemiological report. J Public Health. 2010;18:437-442.

11. Simon FA, Pickering LK. Acute yellow phosphorous poisoning "Smoking stool syndrome". JAMA. 1976;235:1343-1344.

12. Santos O, Restrepo JC, Velasquez L, Castano J, Correa G, Sepulveda E, et al. Acute liver failure due to white phosphorous ingestion. Ann Hepatol. 2009;8:162-165.

13. Ates $M$, Dirican A, Ozgor D, Aydin C, Isik B, Ara $C$, et al. Living donor liver transplantation for acute liver failure in pediatric patients caused by the ingestion of fireworks containing yellow phosphorous. Liver Transplantation. 2011;17:1 286-1291. 